IP Periodica Polytechnica Transportation Engineering

45(2), pp. 77-83, 2017

https://doi.org/10.3311/PPtr.9279

Creative Commons Attribution (i)

RESEARCH ARTICLE

\section{Assessment of the Current Status of Intelligent Transport Systems Serving the Improvement of Road Safety in Hungary}

\author{
Árpád Török ${ }^{1 *}$, Gábor Pauer ${ }^{2}$
}

Received 30 May 2016; accepted 18 August 2016

\begin{abstract}
Reducing the number of road accident victims is a declared purpose of the European Union. The lowering of the number of accidents and victims has a positive financial effect, besides social interests. Intelligent Transport Systems (ITS) can be effective tools to improve road safety by warning and supporting the drivers and decreasing accident risks based on all the three pillars of traffic systems: the vehicle, the infrastructure and the human factor.

The aim of our research was to structure the ITS solutions serving the improvement of road safety based on their characteristics and to analyze exemplary applications from each category. During the analysis - besides the structure of the systems - the presentation of data collection and data processing methods, and linkage options have also been touched upon.

The research highlights the comprehensive opportunities to improve road safety by the presented applications, therefore facilitating public acceptance and revealing the importance of widespread of the Intelligent Transport Systems.
\end{abstract}

\section{Keywords}

Intelligent Transport Systems, road safety, Hungary

\footnotetext{
${ }^{1}$ Department of Transport Technology and Economics, Faculty of Transportation Engineering and Vehicle Engineering, Budapest University of Technology and Economics, H-1111 Budapest, Müegyetem rkp. 3., Hungary

${ }^{2}$ Centre for Road Safety,

KTI Institute for Transport Sciences,

H-1119 Budapest, Thán Károly utca 3-5., Hungary

"Corresponding author, e-mail: arpad.torok@gmail.com
}

\section{Introduction}

The improvement that characterized the accident indexes of public traffic in the past decade, came to a halt in the previous two years. The lowering of the number of accidents, besides social interests, is of crucial importance from the national economy point of view, since it has a positive financial aspect (Török, 2015). The safety improvement potential of the measures and interventions aiming the reduction is finite, so the more and more widespread innovative info-communicational solutions that have undergone outstanding progress recently - are valorized. The new, intelligent methods, by promoting the avoiding of accidents, and by alleviating the seriousness of these accidents, are suitable for subserving the improvement of the traffic safety situation.

The purpose of our research is to analyze and reveal the current status of Intelligent Transport Systems (ITS) affecting traffic safety, in Hungary. Based on the installation and nature of operation of the systems, we created categories, and then one exemplary application is chosen from each category, and is being presented in detail.

\section{Classification of the intelligent solutions affecting traffic safety}

The accident risks can be decreased via ITS solutions based on all the three pillars of traffic systems: the vehicle, the infrastructure and the human factor.

Certain inside-vehicle systems increase the safety of the car by reducing the probability of the supervention of accidents and alleviating the effects of these accidents. Such ITS solutions are, for example, the inside-vehicle driver assistance systems. The so-called e-Call project being implemented on European level, contributes to the improvement of safety by automatic emergency calls during accidents, hereby shortening the duration of saving/rescue activity significantly.

The subservience of the safety of the infrastructure is possible on the one hand with ITS solutions specifically created for this purpose, on the other hand systems primarily serving other functions may also contribute to this. For example, during the tuning of the traffic control systems to the local or network-level 
optimum, the role of the beneficial effects of the traffic characteristics on traffic safety can also be vindicated. The camera systems, traffic signs measuring and displaying speed or warning the drivers about exceeding the speed limit more and more frequently occurring on public roads, based upon data collected on the vehicles, stimulate the drivers to keep the safety rules. With the help of the variable mark traffic signs, hazards can be predicted, and with the help of certain systems (e.g. systems warning about collision or lane departure, accident-focus seeking algorithms) the potential hazardous/dangerous situations and conflicts can be pre-estimated.

The intelligent systems by warning and supporting the driver or via intervention can be applied to decrease the endangering or risking feature of the human factor. With the use of fatiguemonitoring systems or ITS-solutions perceiving affected condition, dangerous traffic situations can be prevented, the data collected by them may also be used by systems of other fields (e.g. police control, databases). On the smart devices more and more widely and continuously used by the drivers direct and tailor-made support and data collection is available.

Considering the above - during the classification of the intelligent solutions promoting the improvement of traffic safety we created the following ITS categories:

1. Systems supporting the keeping of the Highway Code

2. Systems facilitating the real-time and continuous monitoring, tracking and support of the drivers' behaviour

3. Systems for the forecast of hazardous traffic situations

4. Systems supporting rescue activity

5. Unified European electronic driving licence and registry system

6. Traffic control systems

7. Systems serving the creation of the traffic safety characteristics of the transport infrastructure

8. Inside-vehicle active safety systems

9. Inside-vehicle obligatory monitoring systems supporting traffic safety

10. Intervention systems depending on the status of the driver

\section{Assessment of the exemplary solutions belonging to the created ITS system groups}

Along the categories made, we gathered and evaluated the domestically available intelligent solutions. From each group one widespread, exemplary application was evaluated in detail. During the analysis we touched upon - besides the structure of the systems - to the presentation of data collection and data processing methods, and linkage options.

\subsection{Systems supporting the keeping of the Highway Code}

The various speed-meter and display signs and boards, systems warning about the exceeding of the speed limit, and the socalled COMGUARD-system that confirms the Highway Code signs inside the vehicle are included in this group. The VÉDA Public Road Intelligent Camera Network can be mentioned as an exemplary application, which was released recently, and is an infrastructural monitoring and sanctioning unit.

\subsubsection{ITS solution: VÉDA Public Road Intelligent Camera Network}

Description: the system consists of 365 fixed (immobile) and 160 portable intelligent cameras. The Complex Traffic Checkpoints (CTC) work on the entire area of the country, their structure is modular. The system's purpose is to motivate all participants of the public road traffic to keep the rules. The automatic cameras are not only able to measure the speed of the vehicles, but also capable of doing traffic counting tasks, and indicating other critical traffic situations (traffic jams, accidents etc.) as well. They are able to sense the breach of the rules about no entry, obligatory direction (ahead only), use of the stopping and bus lane, crossing a level crossing, and solid white line. They detect the crossings when the traffic lights are red, the omission of the use of the safety belt, and recognize the vehicles carrying hazardous materials ply on the public roads. If they are connected to a number plate-recognizing module, they immediately forward the information about the violations of law to the central system.

Data collection, data processing: data collection is done by the camera units constituting the system. The data concerning violations of law and the traffic data are forwarded to the appropriate authorities (police, public road managers etc.). The data processing is carried out by the central servers of the appropriate authorities.

Assessment: it is a system integrated into the control process of the police, which means that the participants of public road traffic can expect measurements with legal effects. The cameras are connected to the server sub-systems by the central traffic safety automated processing and information system (KAFIR - CTSAPIS), for example with the vehicle registry- or the wanted person database. The operator of the registries is the KEKKH (Közigazgatási és Elektronikus Közszolgáltatások Központi Hivatala - Central Office of Administrative and Electronic Public Services). As an effect of the VÉDA system, the number of traffic-related injuries and casualties and the extent of economic damages will probably decrease. 


\subsection{Systems facilitating the tailor-made, real time, continuous tracking and support of driver behavior}

The different GPS tracking and fleet management systems, the smart devices and the applications developed for these provide an opportunity to track the people in public road traffic in real time and continuously, thus facilitating tailor-made support (Szalay and Aradi, 2015). In our work we present the VEMOCO system in more detail, that collects and analyzes the individual driving characteristics, and which is developed by Hungarian experts.

\subsubsection{ITS solution: VEMOCO system}

Description: it is a complex car safety service. The main elements of the system are the module that connects to the OBD port of the car, the mobile application processing and displaying the retrieved data, an online web service for the same purpose, a 24-hour customer service and a behavior-based insurance meeting the newest trends that can be bound with our partner insurance companies. According to the European Union's regulations, all the vehicles manufactured after 2001 must have the so-called on-board diagnostic (OBD) port. That is what the VEMOCO's module is connected to as well. The reader module has its independent GPS chip, and also communicates with the VEMOCO database through its own closed system covering the whole of Europe. Through this application the relevant fuel consumption can be monitored continuously, and parallel with the real time data warnings in connection with the driving style also arrive (defensive driving style is preferred). For instance, the application indicates if we accelerated too intensively, if we are not in the optimal gear compared to our speed, or we did a too strong braking. The data can be reached both from Android (and iOS) applications, and on a web surface. The 24-hour customer service of VEMOCO continuously has all the information regarding the technical status of the vehicles connected to the system, and also their GPS coordinates. In the case of an accident the system is able to notify the appropriate services and to provide them with data. Besides, in connection with minor problems obstructive to the getting forward of the vehicles, the help of the customer service can be required.

Data collection, data processing: the automobile diagnostic data provided by the on-board computer of the vehicles provide the basis of the system. The processing and display of the retrieved data is possible with a mobile application and a web surface (webpage).

Assessment: The data collected by this system can be utilized very well, for example the Hungarian Post Insurance uses the data of VEMOCO for its casco offers. Via the use of the tool and the connected service, the insurance company can give an offer based on actual risk instead of calculated average risk. It can offer a „Pay as you drive” product to its customers. This way the fee of the insurance not only depends on an averaged piece of statistics, but also on the driver's calmness, orderliness.
Vemoco treats data as strictly confidential, although continuously receives data about the position and vehicle-dynamics characteristics of the cars.

\subsection{Systems forecasting/predicting hazardous traffic situations}

The forecasting of the hazardous traffic situations is an effective tool in the prevention of accidents. Forecasting can be carried out in a tailor-made way (e.g. through the analysis of the individual motion characteristics, and the mapping of the environmental data) or a collective way. Some methods, such as the road meteorological information systems, or traffic signs with variable markings - presented in this article in detail provide an alternative to the latter solution.

\subsubsection{ITS solution: Traffic signs with variable markings (TSVM)}

Description: In some cross-sections of the motorway informative and indicating/warning signs with text or with graphical information are available for the purpose of informing the clientele. The dynamic traffic management systems harmonize the traffic flow, and affect the speed of the vehicles according to the traffic situation. Their purpose is to increase traffic safety and to manage traffic in the case of traffic snarls forming because of unexpected events, traffic jams and unfavourable weather conditions. In an event-free state they can be used to display traffic safety information (they warn us about the use of the safety belt, the keeping of the safety distance etc.) (KHEM, 2009).

Data collection, data processing: This system is not suitable for data collection, only to display them and to give information. Their operation, control and continuous update is carried out centrally (ÁAK PLC.)

Assessment: with the use of traffic signs with variable markings, dynamic traffic management can be realized. The harmonization of the content of the displays is carried out centrally. At the regional radio stations the dispatchers provide information by several reports a day about the current traffic conditions, based on a pre-designed strategy.

\subsection{Systems supporting rescue activities}

The systems supporting rescue activities contribute to the improvement of traffic safety in the case of accidents already happened, by alleviating the seriousness of the consequences. Among these solutions the more and more widespread e-Call automatic emergency call system stands out.

\subsubsection{ITS solution: e-Call Emergency Call System}

Description: The e-Call device must be installed into the automobile. It works as an intelligent phone. It consists of an onboard unit and a SIM-card belonging to the unit. It detects the accident based on the signals of the sensors, locate the position 
of the vehicle using satellite technology, then sends the details automatically (GPS-coordinates, identifier of the motor vehicle, number of passengers, time of accident etc.) to the number 112. The emergency call immediately gets into the emergency center, so the dispatcher can notify the organizations involved in the saving tasks, which can arrive at the scene of the accident sooner this way. The ER center records the data the same way as it had gotten a phone announcement from a citizen. The e-Call can be activated manually by the driver himself/herself.

Parallel with the introduction of e-Call in 2015, the EP obliges the member states (according to 305/2013/EU regulation) to build up the unified network of centers belonging to emergency number 112 (UECS- Unified Emergency Call System). Since the may of 2014 the emergency call centers implemented in the framework of the UECS-112 project in Hungary (in Miskolc and Szombathely) centrally receive the emergency calls coming in on the emergency numbers 112 and 107, among these the ER calls coming from e-Call on-board units (Lindenbach, 2014). The separation of the e-Calls from the other emergency calls and the transmission of the GPS coordinates generated by the On-Board-Units in the lack of the appropriate Hungarian standardization, and in the lack of regulation concerning the relevant obligations of the mobile service providers, still means a lot to do.

Data collection, data processing: Data collection is automatic by the sensors built in the vehicle. The forwarded data are recorded and processed by the emergency call center. Saving or rescue can immediately be started based on these data. The security of personal data will not be damaged, since the device activates only if it detects an accident or the driver activates it manually. The Call Reception Centers preserve the data sent by the e-Call instruments for a determined period of time according to the national regulations and the data protection act. Thus, e-Call in itself does not allow the tracking of the vehicle, because the device is not in constant connection with the mobile networks. The information technology system of the CRCs is prepared for IP-based communication and is supported by a spatial-IT system. The Hungarian service providers currently forward the positional data - determined based on the cell information - on an IP line to the CRC-system.

Assessment: The European Parliament specified in a regulation for the automobile manufacturers that cars and trucks released after 31 March 2018 must be equipped with GPSbased e-Call device. Currently, into the vehicles already used in traffic, it can be installed at the expense of the owner. With the help of the system the time passing between the occurrence and the announcement of the accident can be reduced by approx. 10-15 minutes. According to traumatologic analysis and traffic examinations, the number of people deceased in traffic accidents can be reduced by $2-2.5 \%$. Based on the examinations carried out, $17-18 \%$ decrease can be achieved with e-Call service, concerning the total of the accident-based jams, on the entire national (domestic) road network 3.5\% decrease can be achieved in the total number of jammed hours. Based upon the detailed analysis carried out, with the introduction of the e-Call emergency call system the return-cost ratio that can be achieved is: 1.6-1.9 (Lindenbach, 2014).

\subsection{Unified EU electronic driving license and registry system}

The unified EU electronic registry system as an Intelligent Transport System also contributes to the improvement of traffic safety, however, indirectly. It increases the willingness to follow rules, simplifies the checks and controls, creates the conditions for their automation and improves the possibilities for the sanctioning of foreign drivers. Currently no such wide-spread unified system exists. In Hungary the public road traffic registry is managed by the Central Office of Administrative and Electronic Public Services.

\subsubsection{ITS solution: The national public road traffic registry of the Central Office of Administrative and Electronic Public Services}

Description: Its purpose is the protection of the safety of possession and traffic. The parts of the traffic management's registry are the following: (According to Act 84 of 1999 on the public road traffic registry)

- the license registry,

- the vehicle registry,

- the originality-control registry,

- the Document bay,

- the parking pass registry and

- the preliminary originality-control registry (KSZK, 2009).

Data collection, data processing: This system serves as a registry of data. Data collection is a complementary state function, administrative activity in all cases. State data management and all state data collection are under data protection rules.

Assessment: The database of the registry is a country-level system. Only those organizations and persons are entitled to require data, which and who are determined and listed in Act 84 of 1999 . The application must contain the verification of the purpose and claim of the data usage, and the data sufficient to identify the subject of the data claim. The stored data can be used for the establishment of a unified electronic registry covering the whole of the EU.

\subsection{Traffic control systems}

The traffic control systems do not primarily serve traffic safety purpose, however, during their forming and tuning this point of view may also be demandable. Their presence significantly influences the safety of the network (e.g. safeness of junction conductions). Several service providers' systems can be found in our country. In our article we present the SITRAFFIC system of Siemens. 


\subsubsection{ITS solution: SITRAFFIC traffic control system}

Description: The structure and tasks of SITRAFFIC traffic control system are different according to level. Tasks to be executed on the level of on-field control units (SITRAFFIC C800/C900):

- junction control unit with traffic-dependent programs,

- time- or traffic-dependent signal plan choice,

- preference of public transport.

Central control level (SITRAFFIC Scala):

- junction/nodal control and tuning,

- system monitoring,

- central optimization of signal-control (e.g. with adaptive procedures).

Traffic management level (SITRAFFIC Concert):

- urban / regional traffic management,

- integration of sub-systems,

- integration of urban and regional information,

- central control and monitoring,

- review of traffic information.

Data collection, data processing: data are provided by the on-field devices. The collected data consist of two types: on the one hand the continuous traffic measurements on the road network (loop detectors, video detectors), on the other hand the data provided towards the center (operation signals, error/ malfunction signals etc.) by the installed devices (e.g. traffic lights). The center receives the data, carries out continuous monitoring, and control and the operator's commands can be realized from here. The traffic control center is in continuous online connection with all junctions. Parallel communication allows faster and more reliable report-transmission.

Assessment: Via the traffic management function, the task of the system is to collect the information affecting the completion of the traffic, from optional traffic sub-systems, to represent them transparently for the operating staff, in order to facilitate for them to make the necessary actions and arrangements in due time (e.g. program switches). Among the advantages of the SITRAFFIC traffic control system are: it optimizes the completion of the urban/city traffic (route- and network level fine-tuning); ensures the non-stop operation of traffic lights junctions, supports the running of the traffic lights service, decreases the troubleshooting times; and also serving the traffic management center function (SITRAFFIC Concert module) and the parking control center function (display of vacancies, free capacity). This system is for example applied in Debrecen.

\subsection{Systems for the creation of traffic safety characteristics of the transport infrastructure}

To carry out the analysis of accidents, to create traffic safety strategies the mapping of the safety characteristics of the infrastructure is inevitable. Among these systems we can mention „ROADMASTER-G” which is the road condition recording system of Magyar Közút Rt. (Hungarian Public Road PLC), or the
„KARESZ” public road data collection system. The data coming from these provide the basis for different traffic safety databases (e.g. accident databases), and analyzing methods (such as the EuroRap methodology serving the creation of hazard maps).

\subsubsection{ITS solution: Creation of Hazard Maps (e.g. EuroRap methodology)}

Description: According to the iRAP method, during road assessment first the road is examined, and then the infrastructure elements affecting road safety are recorded. The road section's safety is graded based on this, using a scale from 1 to 5 (star grading). Then the software created specifically for this purpose determines the provisions deemed most suitable for reducing the risks, so that later the safety grade of the given section could be improved. Above these, the databases of hazard maps can serve as the basis for route-offering methods, which consider/take into account the effect of traffic safety parameters.

Data collection, data processing: during the survey the cameras are equipped with high definition (HD) cameras (usually with two or three forward-looking cameras, which cover an angle of at least 160 degrees). The cameras are fixed to the roof of the vehicle, and connected to the computer inside the vehicle. For position determination (localization) a GPS unit is also connected to the computer, and the software connects the pictures with the GPS data. The complete equipment is placed into a specifically modified road-control vehicle. The vehicle takes digital photographs (usually in every 10 meters), while makes progress in the traffic, keeping the speed limit. The position determining (locating) system records the distances (from the given starting point), the latitude and longitude data, the day and time. After the data collection, based on the pictures, the road (route) is "coded" at each $100 \mathrm{~m}$ section, i.e. they check which ones are present among the 52 such known road features, which influence the probability and seriousness of accidents. The background data used for modeling are - among others - traffic density, pedestrian and biker traffic density, speed, accident data, the estimated costs of 94 possible action variation and other economic data.

Assessment: The Safer Roads Investment Plan (SRIP) - for each $100 \mathrm{~m}$ section of road examined - contains the economically justifiable risk-reduction arrangements. The SRIP plans can be well used for the selection of the most cost-effective public road infrastructure by the authorities, the affected ones and investors. Besides this the integration of the databases of the hazard maps into navigational systems can be expected.

\subsection{Inside-vehicle active safety systems}

The reduction of the role of the human factor, that is responsible for the majority of the public road accidents, is possible with the inside-vehicle intelligent systems supporting driving operations (Bayly et al., 2007). The active systems are able to partly or entirely take over, facilitate certain driving operations, 
so besides the increase of the comfort feel of the driver they also improve traffic safety. The automatic/adaptive speedkeeping systems, lane-leaving warning, dead angle monitoring and bump-inhibitor systems or the electronic course stabilizer (ECS) can be mentioned as examples.

\subsubsection{ITS solution: Electronic Stability Program (ESP)}

Description: The role of the ESP is to stabilize the motor vehicle within the limits of physical possibilities in the case of a slip-out, and thus help the driver in getting back the stability over her/his vehicle. The ESP combines the functions of antiblock system (ABS) and the traction control system (TCS) and complements their operation with the "stability servo".

Data collection, data processing: The collection of the necessary data is carried out inside the vehicle. A sensor detects which direction is the steering wheel turned and to what extent (steering wheel position sensor). On each of the four wheels there are sensors, which measure how quickly the wheels are turning (wheel-turn sensors). For the measuring of the swing on the horizontal plain, depending on the mass-center, serves the yaw-rate sensor. The signals of the sensors can be interpreted, compared and determined by the electronics (central unit) and to determine - based on the data - whether the operation is operational. About the necessity of intervention electronics decides, based on its decision the hydraulic unit is capable of the control out of the brake-pressure to the wheels respectively.

Assessment: For its own operation the ESP uses the sensory and interfering elements of the ABS (anti-block brake system), and cooperates with the TCS system. With its individual control, by the braking of each wheel separately (selective braking) or by the acceleration of the actuated wheels the vehicle can be steered. The engine control system equipped with CAN-port is capable of affecting the momentum of the engine and through that the drive-slip of the wheels. The further-developed sub-units of the course dynamical control can - on each wheel - optionally, individually and very accurately control the longitudinal and lateral dynamic forces. In the critical situations thus ESP reduces the danger of crash or roll-over. Within physical limits it prevents the wandering from the road. This way it supports the driver purposefully and increases the safety of public road traffic.

\subsection{Inside-vehicle obligatory used monitoring systems supporting traffic safety}

During the grouping of intelligent systems, we differentiated the compulsorily applicable inside-vehicle systems from the previous category. With the help of these some driver groups' (for example official drivers, beginner drivers etc.) driving attitude can be monitored, surveyed, and tailor-made support can be provided. The most characteristic example of this group is the digital tachograph, the compulsory application of which extends to trucks with the allowed total weight above 3.5 tons and to the passenger vehicles having more than 9 seats.

\subsubsection{ITS solution: Digital tachograph}

Description, structure: The digital tachograph electronically records the times of the driver spent with driving, relaxing and other kind of work activity. These data are contained by both the on-board unit and the card. The former is capable of storing the data of approximately 365 days, while the latter is able to store approx. 28 days. The data on the card are recommended to be downloaded regularly - approx. three weekly - or in every other justified case, in order to avoid data loss. The goal of its application is the stricter adherence of the driving- and relaxing times, furthermore the increase of traffic safety on the public roads, and the establishment of fair competition in the countries of Europe.

Data collection, data processing: Data are collected by the on-board unit (i.e. the digital tachograph itself) and recorded electronically. The tachographs are electronic sensors. They record the speed of the vehicle, the length of the distance driven, the length of each trip separately, the departure and arrival (or stop) date and time of buses and trucks.

Assessment: The European Union determined the introduction of tachographs in a regulation (reg. 2135/98/EC of the Committee, dated: 24 September of 1998.). For the support of the issue and registration of the digital tachograph cards, and for the on-road and premises (on-site) checks of the driving time and sleeping/relaxing time of the drivers an integrated IT system has been established. The system forwards the data determined by the EU regulations to the EU-database thru the TACHOnet network.

\subsection{Intervention systems depending on the state of the driver}

Part of the public road accidents due to human error can be avoided by blocking the driving operations occurring under unfavourable effects (Wecht and Koehler, 2016). The domestic application of the check systems controlling the influence of consciousness-modifying drugs on the driving person before the start of driving is not yet typical. The appearance of the systems blocking driving operations in a drunken state (for example "alcolock" (Bjerre and Kostela, 2008)) is a process expected in our country as well. Fatigue can also be considered an unfavourable effect that can be observed by the inside-vehicle fatigue monitoring systems.

\subsubsection{ITS solution: Fatigue Detection system}

Description, structure: The systems monitoring the fatigue of the driver automatically analyze the driving characteristics, and if some of their signs allude to the fatigue of the driver, they suggest relaxation for the driver. Above a given speed the system continuously monitors the movement of the steering wheel, and other signs inside the vehicle, based on which it estimates the level of fatigue. Above a determined level it warns the driver in a visual and acoustic way. If the driver does not take a nap, then the signal is repeated in fixed intervals. 
Data collection, data processing: The different systems monitor the fatigue of the driver based on different data, for example, by detecting lane keeping, steering wheel movements, speed-ups. The safety belts and seat coatings monitoring the heartbeat and breathing of the driver, and eye- and head movement monitoring devices are also under development (Singh et al., 2011).

Assessment: automatic vehicle systems may apply the data of inside-vehicle sensors (for example: steering wheel turn signaler, which is part of the ESP).

\section{Conclusions}

During our study we categorized the Intelligent Transport Systems supporting traffic safety, and analyzed some outstanding examples from each category from among the domestically applied ITS solutions. Besides the presentation of the structure of each system we also presented the information on data management, going into the details of the connection points of each of these systems.

The studies implemented are suitable to reveal the characteristic lacks of each field. We found out that - in contrast to the examples from abroad - in our country the application of the intelligent systems controlling the influence of consciousnessmodifying drugs on the driving person and blocking the driving operations is not typical. The circle of supporting applications created for the smart devices continuously used by the travellers is also gappy, so the research potential in this field is significant. In order to implement the unified European Union driving license and registry system the data in the traffic registry of COAEPS (Central Office of Administrative and Electronic Public Services) can provide a good basis, however, so far there is no such initiative as the creation of an electronic data medium card which is unified and incorporates the databases of different registries, similarly to the electronic driving license called Smart Card used in the Netherlands with success (Gemalto, 2011).

The extension of the communicational opportunities of the yet in many cases independently operating data systems that produce useful information, and also the spreading of the intelligent solutions in a wider range must provide the base for the strategy concerning the Intelligent Transport Systems (KTI, 2015). During the unification of the communicational channels it is recommended to take the international standardization processes into consideration.

\section{References}

Bayly, M., Fildes, B., Regan, M., Young, K. (2007). Review of crash effectiveness of Intelligent Transport Systems. TRACE, Project No. 027763, Deliverable D4.1.1-D6.2. 2. URL: http://www.trace-project.org/publication/archives/trace-wp4-wp6-d4-11-d6-2.pdf

Bjerre, B., Kostela, J. (2008). Primary prevention of drink driving by the largescale use of alcolocks in commercial vehicles. Accident Analysis \& Prevention. 40(4), pp. 1294-1299.

https://doi.org/10.1016/j.aap.2008.01.010

Gemalto. (2015). The New Electronic Driving License In The Netherlands. URL: http://www.gemalto.com/brochures-site/download-site/Documents/ gov-cs-netherlands-edriving-licence.pdf

Kormányzati Személyügyi Szolgáltató és Közigazgatási Képzési Központ (KSZK). (2009). Nyilvántartási és Okmányigazgatás. (Registration and Administration Act.) Ket.képzés, ÁROP-2009/2.2.7. (in Hungarian) URL: https:/vtki.uni-nke.hu/downloads/Arop/227/ Szakigazgatas/polgari_adat_es_lakcimnyilvantartas/nyilvantartas\%20 es_okmanyiroda_ppt.pdf

Közlekedési, Hírközlési és Energiaügyi Minisztérium (KHEM). (2009). Stratégia az intelligens közlekedési rendszerek és szolgáltatások fejlesztéséhez. (Strategy for the development of Intelligent Transport Systems and Services.) Budapest. (in Hungarian) URL: http://www.its-hungary.hu/dokumentumok/04 itsstrategia_2009januar.pdf

Közlekedéstudományi Intézet (KTI), “ITS Stratégia” Munkacsoport. (2015). Nemzeti ITS Stratégia. (National ITS Strategy.) Budapest. (in Hungarian) Lindenbach, Á. (2014). Az eCall egységes európai vészhívó rendszer hatásai, különös tekintettel a közlekedésbiztonságra. (The effects of e-Call unified European emergency call system, in particular on road safety.) In: Forgalomszabályozási Konferencia, Pécs. May 29, 2014. (in Hungarian) URL: http://docplayer.hu/6167966-Az-ecallegyseges-europai-veszhivo-rendszer-hatasai-kulonos-tekintettel-akozlekedesbiztonsagra.html

Singh, H., Bhatia, J. S., Kaur, J. (2011). Eye tracking based driver fatigue monitoring and warning system. In: India International Conference on Power Electronics (IICPE), 2011. India, Jan. 28-30, 2011.

https://doi.org/10.1109/IICPE.2011.5728062

Szalay, Zs., Aradi, Sz. (2015). Flottamenedzsment rendszerekkel szemben támasztott követelmények az üzemanyag-szállítás területén. (Fleet management systems requirements in the field of fuel delivery.) In: IFFK 2009 konferencia, Budapest. (in Hungarian) URL: http://kitt.uni-obuda.hu/mmaws/2009/eloadasok/ day3/5-szekcio/006.pdf

Török, Á. (2015). Analysing the Connection of Hungarian Economy and Traffic Safety. Periodica Polytechnica Transportation Engineering. 43(2), pp. 106-110. https://doi.org/10.3311/PPtr.7953 